\title{
Landscape/mindscape/langscape: The ephemerality of the digital and of the real in Marlene Creates's video-poems for ice and snow
}

\section{Carmen Concilio ${ }^{1}$}

Accepted: 15 March 2021 / Published online: 15 June 2021

(c) The Author(s) 2021

\begin{abstract}
The present essay aims at illustrating Marlene Creates's web project Brickle, nish, and knobbly (2015), as a key example of Eco-Digital Humanities. First of all, it is a digital work of art made of ice images. Besides, it is also a digital archive meant to salvage a linguistic treasury of local idioms that both name and describe all types of snow and ice formations in Newfoundland, Canada. Therefore, the present analysis proves the special quality and inevitable ephemeral status of this project, for it constitutes a multimodal and multimedia web-archive, subject to possible erasure, or obsolescence in the face of new computer programmes and platforms developments. The archive is also an open instrument for everybody's use: a digital audio-visual (poetic) dictionary, that ultimately functions as a challenge to climate change effects, that might dissolve both the ice formations and the language that accompanies them. Since the real world is no less ephemeral than the world of the web, this contribution also proves how Marlene Creates's artwork envisions and embraces an ecological salvaging of our present and future landscape, mindscape, and langscape.
\end{abstract}

Keywords Eco-digital humanities $\cdot$ Ice $\cdot$ Snow $\cdot$ Climate change $\cdot$ Ephemerality

\section{Introduction}

Web products-websites, web pages, individual posts-are notoriously ephemeral: if not intrinsically, at least in statistical terms. There is always the risk that something might be lost or might be erased from the web, either for technical fallibility or for infrastructural failures. Concern over the ephemerality of web sources and web products started in the early years of the twenty-first century, almost simultaneously, all over the world, yet prompted by the US. If the 1970s

Carmen Concilio

carmen.concilio@unito.it

1 Department of Foreign Languages and Literature, University of Turin, Turin, Italy 
were the years of some of the first videogames created in Silicon Valley, 1991 might be considered the birthdate of websites, 1998 was the foundation year for Google's algorithm, while 2007 was the year of the presentation of the iPhone (Baricco, 2018, p. 318). All of them are quite obsolete now and possibly even not retrievable. It can be said that the intensification of digital technology production is directly proportional to an "archival fever." For instance, in the year 2005, a first attempt to save all existing podcasts took place. Then, in 2010 the Library of Congress in Washington D.C. reached an agreement with Twitter in order to create an all-comprehensive archive (Doster 2016). The purpose was to enable future researchers access to a fuller picture of today's cultural norms, dialogue, trends, and events. Unfortunately, due to the great number of tweets produced per year, the Library of Congress's project has by now become unsustainable. In the US in particular, the second decade of this century saw investments by both universities and public institutions to create archives, particularly as far as social media are concerned. It is worth stressing that Jacques Derrida's reflexions on "Archive fever: a Freudian impression," published in 1995, gave a lasting impulse to theoretical debates and practical strategies in archival praxis and concerns.

Social Media and their platforms are probably more at risk than other websites. For instance, a fairly recent $\mathrm{BBC}$ report claims that tweets easily disappear and with them recent history. "The figures, though, suggest a clear linear trend: the loss of just over $10 \%$ of the resources shared via social media each year, even when archiving is taken into account, or around $0.02 \%$ of this content lost every day" (Chatfield, 2020). As just shown, although not proven, the ephemerality of web objects does seem to determine a certain degree of anxiety. The web is characterized by two extremes: on the one hand the web as archive, as a space to store something forever ("the utopia of permanence"), and, on the other hand, the web as a space of instantaneous consumption and obliteration ("the threat of perishability") (Pesce \& Noto, 2016, p. 2). The latter instance is consistent with the original meaning of the word "ephemera": "Ephemera is the plural form of the Greek word ephemeron (epi=on, about, round; hemera =day). Literally, it refers to something that lasts through the day, which is the case with some winged insects" (Twyman, 2000, p. 7).

An instance of such ephemerality is provided by the African American novelist Teju Cole with reference to Snapchat:

I asked my interlocutor if Snapchat, the photosharing app that causes sent images to disappear after a set number of seconds, would technically be considered photography. The conclusion we jointly reached was that it certainly would: what was important was the possibility of retention, not actual retention itself. A technology that simply did not have the ability to save the images it was transmitting would be more revolutionary. (Cole, 2016, pp. 199-200)

The web might stop producing ephemera only when and if it is capable of retaining its products. In the past and still today, art objects were and are considered eternal, and museums are the chosen places where they might be preserved 
forever. However, earthquakes, flooding, infrastructural collapses might destroy museums just as a fire or a short-circuit might switch off a server. In this context, the emergent field of Eco-Digital Humanities comes to the rescue as far as archival care is concerned, insofar as it developed from the mingling of the environmental humanities and the digital humanities. Both are known for being interdisciplinary and collaborative; challenging business-as-usual scholarship by imagining new forms and employing new media for academic work; emphasizing making, composing, retrofitting, and repairing over unsustainable cycles of innovation; valuing archiving and preservation while looking to forge the future (Cohen \& LeMenager, 2016, p. 131).

The stress on "archiving, preserving and storing" is the challenge that this new genre has chosen to tackle. Since, art objects created for-and published on-the web are not necessarily eternal. Philippe Bootz claims that obsolescence is a keyword that defines "the digital apparatus and leads us to think that every artistic work crated with the latter is completely and inherently ephemeral (Bootz, 2014, p. 1). The concept of ephemerality, however is even more relevant when it is attached not so much to the virtual and dematerialized object re-produced and re-presented on the web, but to the real one; not to the copy or the replica but to the original and authentic object of inquiry. In this essay, it is the concept of "ephemerality" that is relevant in relation to multimodal and multimedia web products and their corresponding real objects of scrutiny, and not the nature of traditional ephemera. The latter are normally related to those fragments and scraps of collectable items celebrating, advertising, announcing and accompanying the publication of texts, the release of films and theatrical productions, dance shows, or the launching of art exhibitions. Nowadays, a new category is needed in order to refer to ephemera productions that are destined to the web: such as digiphemera, that will co-exist in future collections together with more traditional paper and printed ones (Whiting, 2010). Most importantly, the challenges promoted by Eco-Digital Humanities-as defined by Cohen and LeMenager: "developed from the mingling of the environmental humanities and the digital humanities" (2016, p. 340)—will be the framework here adopted.

\section{Marlene Creates's video-poems for ice and snow: web and real ephemera}

Marlene Creates is a poet, photographer and environmental artist, who mainly works in the open air, in nature, in all seasons. She lives in Newfoundland, on the Atlantic coast of Canada and since she is particularly sensitive to the special and unique landscape around her, she is also particularly sensitive towards ice and snow. The landscape she inhabits is made of rocks: very ancient, volcanic rock formations that date back to the Precambrian Era. It consists of trees, shrubs and bushes, grass, lichens and moss, which form the characteristic belt of sub-arctic Boreal forest. It comprises the oceanic waters, of their currents and peculiar metamorphic behaviour, when they turn into drifting ice. All these elements come together with equal strength and suggestive power into her poetic and artistic works. In particular, her artwork "From the ground tier to a sparrow batch, Blast 
Hole Pond River, winter 2012-2013" is worth analysing here, in this context of an academic forum on digital ephemera, or, better, the digital as ephemeral perse.

Marlene Creates's video-poem is an extremely original and fascinating example of a project in Eco-Digital Humanities. First of all, it must be stressed that this literary, photographic, filmic artwork-originally presented at film festivals and now posted on the web-also became a traditional album in print, that can also be browsed as a flip-book: Brickle, nish, and knobbly: A Newfoundland treasury of terms for ice and snow (2015). In the words of the artist, the web-project takes the form of a video long poem, in line with the typical North American tradition of long poems:

"From the Ground Tier to a Sparrow Batch, Blast Hole Pond River, Winter 2012-2013" is a long poem in 40 parts, which also exists in the form of a 26-minute-long documentary video-poem. It proceeds chronologically through a winter, following the meteorological events along the Blast Hole Pond River. [...] A small waterfall, seen from the same fixed viewpoint throughout the season, serves as a refrain. (The top right-hand corner of the book can be flipped to create an animated effect of the waterfall). (Creates, 2015, p. 7)

When starting to analyse this first aspect and layer of the project, it must be noticed that in the video-poem, a lyric I describes a small spot of land, close to a waterfall, all through the winter season, from the announcement of the very first snowfall. In a sense, this is a serial work, documenting the changes, almost day by day, that the landscape undergoes after each new snowfall. The sequencing and repetition of images is therefore also an archival documentary on meteorological data, over a winter season. Critics, commentators and art curators also acknowledge the serial, repetitive sequencing technique in Marlene Creates's works. In her art: "repeated imagery links the viewer with the cyclical processes of the natural world." Creates's "aesthetic ecology is resonant of modernist and minimalist principles: simplicity, economy, seriality, and, I would add, sufficiency" (Gibson Garvey, 2017a, p. 11 and 2017b, p. 16; original emphasis).

In addition, in the video-poem, the lyric performing-voice proceeds in its description of the weather conditions, first as they are officially broadcast, then as they are commented upon by locals, and subsequently the poet describes the effects they produce in the physical world all around. Thus, her poem, softly and slowly recited, over the background of the noise of the waterfall and of running water splashing against rocks and boulders, "sings" the land, embedding local lore into the poetic discourse, also including words and idioms that are typical of the local vernacular. It is particularly this latter aspect of the artwork that has attracted most comments:

Language, spoken and written, formally entered Creates's production in the mid-1980s, in stories of ancestral lands and remembered places. [...]

The sound-sense and shape of words in specific locations and vernacular forms are savoured [...] illuminating this range of linguistic concerns. (Gibson Garvey 2017a, p. 11.)

...language, too, has become primary. [...] in the sound-shapes of words, in the evocative resonance of local vernacular terms, in the participant-listening 
events that bring the whispers and reverberations of the boreal forest together

with spoken and musical gestures by guest performers, and in her own sitespecific poetry. (Gibson Garvey, 2017b, p. 20)

Words and lexical items are therefore most relevant in this poetic text and they introduce a second feature or layer in the project. The presence of a vernacular item interrupts the flow of the video-poem and introduces an alternative performative and explanatory mode. In particular, the signified the poet has chosen to name appears first of all as reproduced by a beautiful and aesthetically admirable artistic still image in colour, which portrays details of a specific ice formation. As a consequence, the corresponding signifier, the printed lexical item that names the object under scrutiny, is placed below the picture as if it were a caption. This lexical item in the local dialect corresponds to the Dictionary of Newfoundland English entry, whose definition is contrapuntally read aloud by a male voice: the poet's cousin.

A whole series of seasonal phenomena are thus observed and recorded by means of over 50 named varieties of ice, snow, and winter weather. "These terms are precise, practical, evocative, sonic and lyrical. And knowing them helps us actually see different phenomena, instead of winter being just a cold, white blur" (Creates, 2015 , p. 7). To sum up, technically speaking, this work of art is the result of moving images and still images, a female voice reciting a poem in a dialogue with a male voice speaking out the Dictionary entries and their corresponding definitions. The filmic and photographic objects are ice and snow, while the subject matter of the long poem is richer, it is a reflection both on objective and on perceived meteorology, on nature's metamorphoses, on an ancient landscape and ecosystem of the heart, of the mind and of the tongue. All this is visible and audible on the web. It is an experience of the senses, suitable also for visually- or hearing-impaired subjects, who might take advantage from one or the other media.

Indeed, the more traditional reader of the corresponding album in print misses the natural sounds of water and wind, and the quality (tone, modulation, inflection) of the human voices. This composite project matches the principles regulating EcoDigital Humanities, that is to say, striving "for a multimodal rhetoric that achieves depth of communication" (Cohen \& LeMenager, 2016, p. 345). Affectively, the socalled phatic function of the message is by no means excluded from this communication. On the contrary, it is an inevitable part of the typical augmented reality of this web project. Both the artist's voice and her camera seem to caress the landscape, while the eye of the digital spectator is invited to slide slowly down the snowy or icy landscape, according to the moving image and the guiding soundtrack.

What is the scope of this project, then? How can we define it? This is a literary project, for it represents a new "literary" genre: digital-literature, or web-literature, or e-literature. It is therefore a composite, multimodal and multimedia digital videopoem (Concilio, 2012). As claimed above, it is a case of augmented literature, for the text as such is perceptible in a multimodal experience that is made up of words and images, tones and sounds, performance and didactic exemplification, all contextualised within a specific visually live ecosystem. We are still in the realm of literature, but it is a literature which becomes most effective in its communication on the web. 
Strictly speaking, this project is also an illustrated dictionary available on the web. In this specific case, the lexicographic project is intended as a digital archive for the benefit of present and future users, meant to fight digital obsolescence and ephemerality. Moreover, this lexicon has been selected from the already existing Dictionary of Newfoundland English published both in digital form and in print (Story et al., 1990), with which it establishes an effective intertextual and cross-referential link. More precisely, Creates's art project generates a new sort of hypertext, for it produces in its digital version a web page linked to other web pages, or else a web page connected with a printed dictionary. Possibly, this project might also be defined as "augmented dictionary." All these lexicalizations, forms of textualities, and video photography create a whole complex interdisciplinary "narrative ecosystem" typical of web products (Pesce \& Noto, 2016, p. 2). In particular, this complex environment is made up of lexicography, poetry, geology, glaciology, meteorology. This new hypertext, or, better, textual poly-system, also allows a new form of memory, which scholars Pesce and Noto define, with Andrew Hoskins, as "connective memory: that is a practice of remembering based on multiple interactive trajectories supported by the abundance and accessibility of communication networks" (Pesce \& Noto, 2016, pp. 2-3).

A dictionary is meant to last for a long time, particularly in its printed version. New versions of the same dictionary document all the changes a language undergoes. With the passing of time and the adaptation to new realities, words might fall into oblivion or become obsolete. Borrowings would add to the sum total of existing words. Neologisms might become part of common usage, or words might even change their meaning, according to a number of variables: use, users, time, space. On the contrary, web projects are perceived to belong to the doomed category of ephemera, for sooner or later they will disappear, due to technical or infrastructural breakdowns, obsolescence of terminals which no longer read old data, or no longer support pre-existing platforms, websites, or old programming codes.

Thus, Marlene Creates's literary-lexical archive of terms for ice and snow presents itself as a fragile product of our times, threatened by "digital extinction." Yet, its ephemerality is even more serious than that. Its "endangered" infrastructural status matches the ephemerality of its object of enquiry: ice and snow in the sub-Arctic regions, which are also doomed to disappear. The author is very well aware of this possibility, when she claims:

This vocabulary is now a fragile intangible artifact. The loss of local linguistic complexity is a result of major changes in Newfoundland and Labrador, particularly the decline of the fishery as an occupation. And these terms are fragile for another reason—climate change. (Creates, 2015, p. 7)

Moreover, the attention to "vanishing languages" is precisely a concern in EcoDH studies as an action of global language preservation: "Languages, although not precisely analogous to species, also have an ecology. [...] Languages have a home and a habitat that can be threatened, and preservation efforts must look at the entire habitat" (Harrison, 2010, p. 89). Marlene Creates's work is a compendium of poetry, film, lexicography, artistic photography, glaciology, landscaping, climate change digital humanities, and environmental literature. It is gender 
balanced, for the voice of a woman and the voice of man take turns in a dialogical recital. It is a complex, multimodal, multisensorial, and multimedia art object, involving visual and auditory materiality, aesthetic abstraction, linguistic accuracy and specificity, due to the reference to a well-localized dialect. It is made up of film (moving images) and photographs (still shots), poetry, captions, dictionary entries, written and spoken words, in the spirit of Eco-DH.

The ecological digital humanities attempt to rethink narrativity by staging different kinds of stories, oscillating between scales, and involving diverse participants in unfolding and recording nonhuman phenomena

Activating more of the human sensorium than text alone typically does, projects in the ecological digital humanities are often visually rich. They can also be aurally dense and based on collaborative fieldwork (they bring embodied place to networked ecologies). (Cohen \& LeMenager, 2016, p.

Literally, this project-if considered as an illustrated dictionary-deserves some further consideration. A dictionary is an archive, determined by specific spatial and temporal coordinates. Marlene Creates speaks of the local terms for ice and snow as a "treasury," thus creating a link between the original meaning of the word, "a collection of highly valued poems," and a second meaning: "a collection of highly valued poetic terms." Thus, she attributes also a sentimental or "aural" meaning to her choice of words reflecting her world.

The loss of a landscape is also likely to entail the loss of a language. The melting of the polar ice caps and the change in climatic manifestations inevitably involve dramatic changes in the morphology of our Planet. What will be lost is both a territory and a thesaurus, a patrimony in both water and words. This is therefore also a matter of linguistic ecology: to safeguard "vulnerable mother tongues" (Hsy, 2016, p. 379). Digital archives, if well preserved, if still readable, will be our only archaeo-landscape/mindscape/langscape in the future. As Choen and LeMenager suggest:

Environmental justice and activism are the fabric of the ecological digital humanities, the aim of which is not simply to catalogue the vanishing things of the past and the present but also to alter the future. Preservation and curation are intimately connected to critical sustainability and revitalization. (2016, p. 345)

Let us select a few instances of how Marlene Creates's poly-system works, "cataloguing the vanishing things" and in the meanwhile trying to "alter the future." The first suggestive element is the spoken poem, as in the lines: "I wonder if this will be the ground tier- / the last snow to melt into the river / next spring" (poet's voice). The second textual layer is a photograph with the following caption and voice-over: "The ground tier is the snowfall that stays all winter, as opposed to the earlier temporary ones" (male voice). So far, the digital spectator has accomplished the two steps of the endogenous experience of the presentation. Yet, should the viewer be curious to check the existing on-line Dictionary 


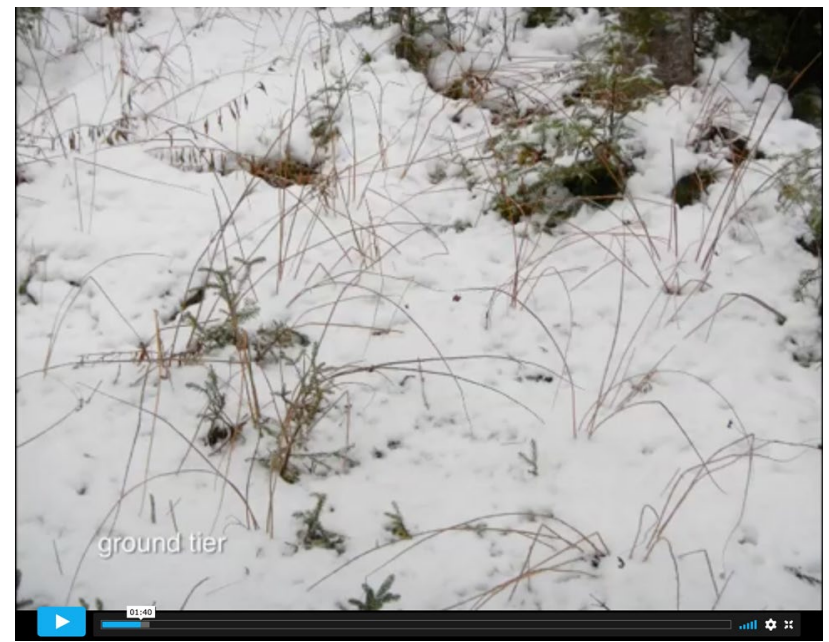

Figure 1 Still image from Marlene Creates's video-poem "From the Ground Tier to a Sparrow Batch": https://vimeo.com/89396222. (01:40)

of Newfoundland English, the spectator's third exogenous step would lead to the following intertextual or, even, hypertextual cross-reference: “tier n. Cp NID ${ }^{1} \mathrm{n}$ 1 'a row, rank, or layer of articles.' Layer.' Fig. 1.

In this example, the local idiom "tier" is easily found in a dictionary, but not the phrasal combination "ground tier." The simple one-to-one-definition "layer" does not provide a satisfactory meaning to the adjectival phrase "ground tier." Therefore, in this case a dictionary falls short in providing the more comprehensive definition. As this case shows, local knowledge is cunning and produces a meaning to the noun phrase "ground tier" that has to do with the quality of the permanence that this layer of snow on the ground characteristically detains. It is "the snowfall that stays all winter, as opposed to the earlier temporary ones" (Creates, 2015, p. 14). It is this knowledge, this qualitative note, and not its denotative signified, that the poet translates into lines.

Thus, what cognitivists Hofstadter and Sander in their Surfaces and essences (2013) write about dictionary definitions becomes evident. They claim that dictionaries do not exhaust the meanings of a single word/concept. For common words/concepts have an unlimited number of meanings. Rather than providing us with the right definition, dictionaries open up an abysmal chain of complexity-conclude the two scholars. "Ground tier" is precisely an example of such complexity.

Two more examples deserve analysis in this context: "young ice" and "new ice." Apparently, and to unaccustomed ears, they might sound synonymous. "Young ice" is better illustrated by the artist's photograph, as a uniform, compact, flat layer of ice that at first sight might look perfect for skating. The photograph's caption and the Dictionary entry recite: "Young ice is newly formed, level ice 


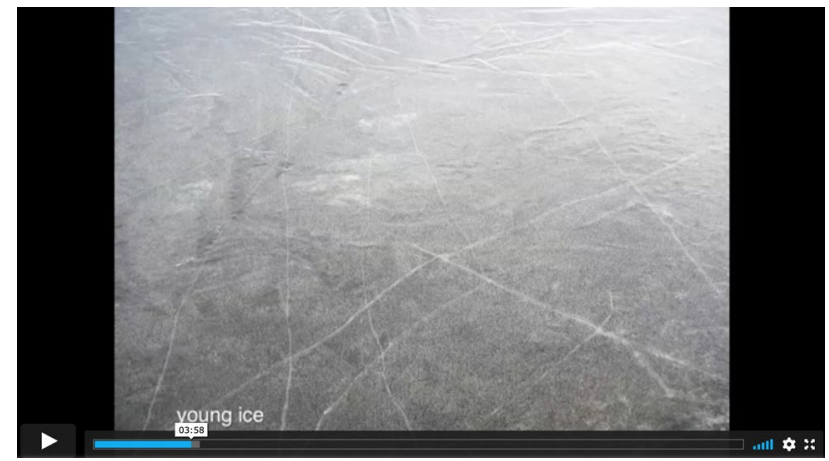

Figure 2 Still image from "From the Ground Tier to a Sparrow Batch": https://vimeo.com/89396222. $(03: 58)$

from two to six inches thick, generally in the bays and harbours, and is unsafe for travel" (Creates, 2015, p. 24).

The fact that this layer of ice is "unsafe," no matter how thick, is something local inhabitants know by experience or because the information has been passed on to them from previous generations. Yet, this is a metaphoric, figurative meaning that sees youth as an unsafe age, risky and hazardous. The next stage to illustrate the concept is the poet's recital (Fig. 2):

Upriver, Blast Hole Pond

has almost caught over

but loud cracks through the young ice

of five nights freezing

startle the silence.

It's December $3^{\text {rd }}$ and this afternoon my neighbour said,

When the sun crosses the line on the $21^{\text {st }}$ we'll see what kind

of winter we're going to have. If the wind is from the northeast,

look out. But if it's from the southwest or anything from the south,

it will be a warmer winter. That's what my poor old dad used to say.

He wasn't wrong very often." (Creates, 2015, pp. 24-25)

The poem adds a piece of information, mentioning the loud sounds, in contrast with silence, that the cracks produce in the ice surface. Thus, the ice easily breaks and consequently cannot be trusted to sustain heavy weights. The printed and the on-line Dictionary entry reads: "Of ice, thin and newly-formed on river, lake or sea, cp. YOUNG: young ice." Moreover, the examples provided allude to young ice as a sign of the end of summer and the beginning of winter, as if it were synonymous with "early" ice.

As for "new ice," the artistic colour photograph has just a very lapidary caption: "New ice is recently formed ice." This neutral definition is also present 


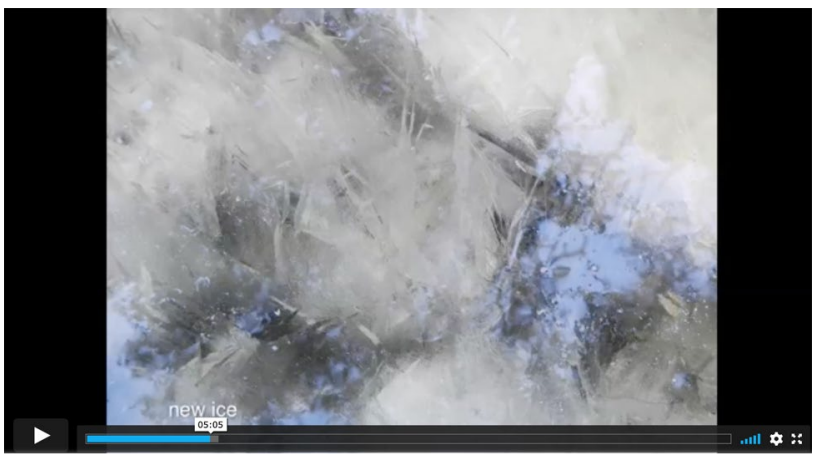

Figure 3 Still image from "From the Ground Tier to a Sparrow Batch": https://vimeo.com/89396222. (05:05)

in the poem accompanying the photographic illustrations in the printed album (Figure 3):

Then this morning, all the way down the path, I can tell the cold has clamped down on the river's run though quicker water till flows past new ice at the edges. I wonder if it will disappear under the expected snow tonight.

A woman at the post office said, "Hopefully it won't be as bad as the forecast. We need a tiny bit of snow for Christmas. But just a scad." (Creates, 2015, pp. 28-29)

At first, the on-line Dictionary also provides a similarly neutral definition: "Of ice, recently formed as the water freezes or 'catches over.' LOCAL: local ice." Yet, the usage samples add more elements that contribute to characterize the ice as breakable or even dangerous: i.e. "Only in new ice can the harp bore bobbing holes." [1964, BLONDAHL ed 84 The loss of the Ellen Munri. "And now to close, take this advice: Don't ever trust the new-made ice."] Synonyms or not, both expressions are richly evocative and metaphoric. The intertext produced by Creates's artwork and by the Dictionary (both the printed version and its on-line version) is a rich archive, in pictures and in words, including poems but also local lore and wisdom, proverbs, idioms, sayings. 


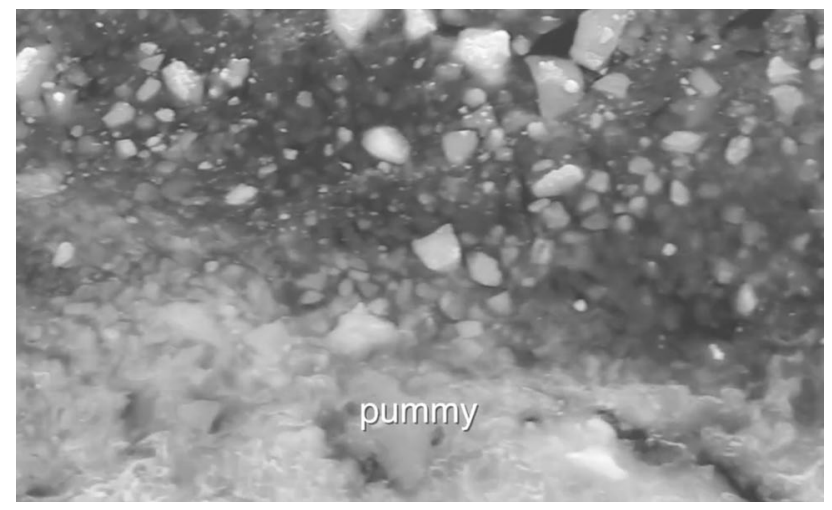

Figure 4 Still image from "Sea Ice, Conception Bay, Newfoundland, March 2014": https://vimeo.com/ 169694402 (00:48').

\section{Conclusions}

In conclusion, climate change is a threat for northern and polar ice, polar ice caps melting and the disappearance of icebergs can change the landscape forever. In this case, a similar and consequential loss of words would occur. Another one among Marlene Creates's projects shows the same dramatic consequences of this loss of words and water, by accumulating a list of nouns and definitions for sea ice formations, while crossing a stretch of ocean water by ferry and filming the patches of different ice as the ferry passed through them. The project is entitled Sea ice, Conception Bay, Newfoundland, March 2014. The only sounds are the wind, the ferry's engine, and the ferry passing through the ice. Local terms are superimposed over the various ice formations. These words create a never-ending sentence, a string producing silent meanings to name-and thus to counter-the melting ice formations (Fig. 4).

If looked up in the Dictionary of Newfoundland English, the first lexeme appearing in the video is thus explained: "pummy $\mathrm{n} \sim \mathrm{A}$ pulpy, squashed mass; phr go/ reduce to pummy." In this case, too, the aim of the artist is to create a contextualized archive, an augmented illustrated dictionary of a specific meteorological condition in a specific year, that documents phenomena that are not rare, but that are threatened with becoming unrepeatable. Similarly, such words are doomed to fade away from human memory and usage.

Language would be impoverished, terms for ice and snow would become obsolete, redundant, and would eventually fall into oblivion (Concilio et al. 2020). For instance, in Iceland the disappearance of a glacier, the first to be lost to climate 
change, has led the population to hold a proper "funeral" and to place a plaque entitled "A letter to the future" both as a memento and as a warning to raise consciousness on the irreversible effects of climate change, also due to a record level of carbon dioxide measured in May 2019 (415 ppm CO2). ${ }^{1}$ Similarly, American climate activist and art photographer James Balog recorded the disappearance of a glacier, thanks to his rich technical equipment strategically distributed in the landscape and time-lapse photography, during his risky expeditions to Iceland. He managed to record a crashing wall of ice: "this is the memory of the landscape. That landscape is gone and it will never be seen again in the history of civilization, and it is stored in a memory stick." 2

All this demonstrates that our fragile landscapes might be even more ephemeral than web archives. Balog's memory stick or Marlene Creates's web projects, as new types of archives, but also as new models of e-literature, will preserve our present as a compelling multi-layered experience for future actions, thus responding to the purpose elicited by Eco-DH ethics and poetics. Both the on-line and the printed Dictionary of Newfoundland English are archival treasures per se, "consigned" to the future as-quoting Derrida— "a single corpus, in a system or a synchrony in which all the elements articulate the unity of an ideal configuration" $(1995,10)$. The creative and artistic reformulation of the Dictionary within Creates's video-poems and recitals for the web is a new frontier of literary heritage (landscape, mindscape, langscape), and a new invaluable blending of the Environmental Humanities and the Digital Humanities.

Literature and the arts, and the study of these disciplines with the tools offered by the digital environment are indeed a way to leave a footprint on our planet. Indeed, this, too, is an anthropogenetic action and performance, but it is oriented, among other things, to allow at least the realization within 2030 of goal 13 of the Sustainable Development Agenda: "take urgent action to combat climate change and its impacts."

Funding Open access funding provided by Università degli Studi di Torino within the CRUI-CARE Agreement.

Open Access This article is licensed under a Creative Commons Attribution 4.0 International License, which permits use, sharing, adaptation, distribution and reproduction in any medium or format, as long as you give appropriate credit to the original author(s) and the source, provide a link to the Creative Commons licence, and indicate if changes were made. The images or other third party material in this article are included in the article's Creative Commons licence, unless indicated otherwise in a credit line to the material. If material is not included in the article's Creative Commons licence and your intended use is not permitted by statutory regulation or exceeds the permitted use, you will need to obtain permission directly from the copyright holder. To view a copy of this licence, visit http://creativecommons.org/licen ses/by/4.0/.

\footnotetext{
${ }^{1}$ Cf. https://www.theguardian.com/world/2019/aug/19/iceland-holds-funeral-for-first-glacier-lost-toclimate-change.

${ }^{2}$ Cf. https://www.youtube.com/watch?v=eIZTMVNBjc4.
} 


\section{References}

Balog, J. (2012). Chasing ice. Retrieved December 5, 2020, from http://jamesbalog.com/about-james/ Baricco, A. (2018). The game. Einaudi.

Bootz, P. (2014). Digital literature: Ephemeral in truth? Journal Hybrid, 1, 1-14.

Chatfield, T. (2020). The decaying web and our disappearing history. (18 November 2014). Retrieved 5 December, 2020, from https://www.bbc.com/future/article/20120927-the-decaying-web

Cohen, J. J., \& LeMenager, S. (2016). Introduction: Assembling the ecological digital humanities. PMLA, 131(2), 340-346.

Cole, T. (2016). Known and strange things. Faber and Faber.

Concilio, C. (2012). Marlene Creates's eco-consciousness as land. Artist, photographer, and poet. In C. Concilio (Ed.), New critical patterns in postcolonial discourse (pp. 65-106). Trauben.

Concilio, C., et al. (Eds.). (2020). Neve e ghiaccio: Itinerari tra variazione linguistica e incidenza climatica. L'adieu des glaciers: A photographic and scientific study. Exhibition Catalogue (pp. 118-119). Forte di Bard.

Creates, M. (2015). Brickle, nish and knobbly: A Newfoundland treasury of terms for ice and snow. Boulder Publications.

Creates, M. (2017). A Newfoundland treasury of terms for ice and snow 2011-2014. In S. Gibson Garvey, A. Kunard (Eds.), Marlene Creates: Places paths and pauses (p. 167). Goose Lane Editions.

Derrida, J. (1995). Archive fever: A Freudian impression. Diacritics 25(2), 9-63. https://www.jstor.org/ stable/465144

Doster, A. (2016). Saving digital ephemera. January 4, 2016. American Libraries Magazine. https://ameri canlibrariesmagazine.org/2016/01/04/saving-digital-ephemera/

Gibson Garvey, S. (2017a). Introduction. In S. Gibson Garvey \& A. Kunard (Eds.), Marlene Creates: Places. paths, and pauses (p. 11). Goose Lane Editions.

Gibson Garvey, S. (2017b). Written in the land. Present in the place. In S. Gibson Garvey \& A. Kunard (Eds.), Marlene Creates: Places, paths, and pauses (pp. 15-21). Goose Lane Editions.

Harrison, K.D. (2010). The last speakers: The quest to save the world's most endangered languages. National Geographic.

Hofstadter, D., \& Sander, E. (2013). Surfaces and essences. Basic Books.

Hsy, J. (2016). Language ecologies: Ethics community and digital affect. PMLA, 131(2), 373-379.

Pesce, S., \& Noto, P. (Eds.). (2016). The politics of ephemeral digital media. Permanence and obsolescence in paratexts. Routledge.

Story, G. M., Kirwin, W. J., \& Widdowson, J. D. A. (Eds.). (1990). Dictionary of Newfoundland English. (2nd ed., p. 982). University of Toronto Press.

Twyman, M. (Ed.). (2000). Maurice rickards. Encyclopedia of ephemera. Routledge.

Whiting, C. (2010). Digital ephemera. Wednesday May 5, 2010. Bibliophemera. https://bibliophemera. blogspot.com/2010/05/digital-ephemera.html

Publisher's Note Springer Nature remains neutral with regard to jurisdictional claims in published maps and institutional affiliations. 